\title{
MAPPING POTENTIAL HABITATS FOR ARTHROPOD VECTORS OF TRYPANOSOMIASIS INFECTION IN NORTHERN NIGERIA: AN INTRODUCTORY SYNTHESIS.
}

\author{
H. A. Umar ${ }^{1,2}$, M. F. Abdul Khanan ${ }^{2, *}$, D. A. Umar ${ }^{1,3}$, M.S. Shiru ${ }^{1,4}$, M. Isma'il ${ }^{5}$, M.R. Mohd Salleh ${ }^{2}$, A. Abdul Rahman ${ }^{2}$, A. \\ Ahmad $^{2}$, and Okoli, E.A ${ }^{6}$. \\ ${ }^{1}$ Department of Environmental Sciences, Faculty of Science, Federal University Dutse, P.M.B 7156, \\ Dutse, Nigeria - H.A.U.- abdulhafizamin@yahoo.com \\ ${ }^{2}$ Department of Geoinformation, Faculty of Built Environment and Surveying, Universiti Teknologi Malaysia, 81310, Johor Bahru, \\ Malaysia - *M.F.A.K.- mdfaisal@utm.my, A.A.R.- alias@utm.my, M.R.M.S.- radhiems90@yahoo.com.my, A.A.- \\ anuarahmad@utm.my \\ ${ }^{3}$ Faculty of Environmental Studies, Universiti Putra Malaysia UPM, 43400 Serdang, \\ Selangor, Malaysia - D.A.U.- abbaumardau@yahoo.com \\ ${ }^{4}$ Department of Hydraulics and Hydrology, Faculty of Civil Engineering, Universiti Teknologi Malaysia, \\ 81310, Johor Bahru, Malaysia - M.S.S. -shiru.sanusi@ gmail.com \\ ${ }^{5}$ Department of Geography and Environmental Management, Ahmadu Bello University, Zaria, Nigeria - M.I. - \\ mgeogjameel@yahoo.com \\ ${ }^{6}$ Department of Geology, Federal University of Technology Owerri, Owerri, Nigeria - O.E.A. -okoliausteen@ gmail.com
}

KEY WORDS: Trypanosomiasis, Tsetse Fly, Northern Nigeria, Normalized Difference Vegetation Index, GIS

\begin{abstract}
:
This paper presents an introductory synthesis for mapping potential habitats of arthropod vectors responsible for animal trypanosomiasis diseases in Northern Nigeria, where there is high production of livestock. Animal trypanosomiasis is considered an arthropod-borne viral disease which is endemic in 36 countries of sub-Saharan Africa and particularly in northern Nigeria. The disease which is transmitted by the vector tsetse fly remains a threat to both humans and livestock in many rural communities of Nigeria. The outbreak of the disease is known to occur as a result of the changing climate which relates to changes in sea surface temperatures otherwise known as 'El Niño Southern Oscillations' (ENSO). Trypanosomiasis is mainly experienced whenever there are changes in global precipitation as a result of the changing climate. Monthly Satellite data of Normalized Difference Vegetation Index (NDVI) at $2.5^{\circ}$ spatial resolution was sourced from NASA- MODIS/CMD and subjected to principal component analysis using standardized principal components of GIS with a digital elevation model (DEM) supplemented in the analysis. Results revealed pockets of probable habitats of arthropod vectors to be around forest islands characterized by dry woodland and savanna, and in other cases around gallery forests and few lowland and riverine areas. This study demonstrates that geospatial technology is a cost effective tool in mapping of the arthropod vector habitats for Northern Nigeria.
\end{abstract}

\section{INTRODUCTION}

Climate change has been responsible for changing of the rainfall and temperature patterns, and the intensity and frequency of disasters across the globe in recent times (Shahid, 2010; Thomas and Lopez, 2015; Shiru et al. 2018). These changes which has also been felt in Africa, shows that there is interannual variability in the West African monsoon (WAM) which is greatly affected by the remote influence of El NinoSouthern Oscillation (ENSO) (Joly and Voldoire, 2009).

The spatial range of vector borne diseases can be altered as a result of the changing climate by a shift in the geographical location of their vectors (Hunter, 2003, IPCC, 2007). Wildlife and human diseases such as cholera (Colwel, 1996; Pascual et al., 2000), malaria (Hay et al., 2002; Pascual et al., 2006), West Nile virus (Daszak et al. 2000), and Amphibian Chytridiomycosis (Pounds et al, 2006) have been reported to have emerged, re-emerged, and expanded in range as a result of the changing climate (Moore et al., 2012). Another disease that can spread geographically as a result of the changing climate is trypanosomiasis; a disease transmitted through its vector, Tsetse fly. Trypanosomiasis can occur in animals, the type known as
'Animal Trypanosomiasis' and in humans, 'Human African Trypanosomiasis' as it is commonly known. The disease is endemic in 36 countries of the sub-Saharan Africa and remains a threat to both humans and livestock in many rural communities ( $\mathrm{Yu}$ et al., 1995). It is an infectious disease, usually progressive and fatal if untreated, and, its vaccine production has remained a challenge (ILRAD, 1993; La Greca and Magez, 2011).

A range of temperature $\left(16^{\circ} \mathrm{C}-38^{\circ} \mathrm{C}\right)$ and humidity $(50-80 \%$ relative humidity) is needed for the survival of tsetse flies (Franco et al., 2014). They thrive in the presence of water which increases local humidity preventing them from direct sunlight and attracting animals to them due to vegetation growth (WHO, 2013). Therefore, the outbreak of the disease relates to the fluctuation in climate in which sea surface temperatures also known as the 'El Niño Southern Oscillations' (ENSO) phenomenon changes (Roger and Randolph, 1991). The change in global precipitation and biomass coincides with this period. During this period, the vectors and their parasites can breed, develop and transmit the trypanosomiasis disease particularly when they inhabit forest islands characterized by dry woodland and savannah, and in other cases around gallery forests. One of 
the control strategies for Trypanosomiasis disease is to eliminate or minimize the fly-to-man or fly-to-host contact of tsetse fly. By this, a protective barrier in which a control scheme is employed to prevent the spatial progression of Trypanosomiasis is created (Matzke, 1983; WHO, 1986; Buxton, 1995).

In line with such efforts to control the endemic disease of Trypanosomiasis, studies (Laid, 1977; Dransfield, 1991) have been conducted to understand the dynamics of tsetse flies and in different parts of Africa using various methods including capture-recapture experiments. Roger and Randolph, (1991) used data acquired through remote sensing technology to have a better understanding of the flies' movements. It was shown that the outbreak of disease relates to changes in climatic conditions of an area. Other studies (Anyamaba, 1994; Anyamba, and Eastman, 1996; Sutherst, 1998; Anyamba et al, 2001; Anyamba et al, 2002) have also indicated that changing environmental conditions has led to changes in how and where plants, animals and humans contracted diseases.

Principal Component Analysis (PCA) which employs the standardized principal components in environmental studies when remotely sensed data is administered in GIS has indicated that the major element of variability is that which occurs spatially (Singh and Harrison, 1985; Eastman and Fulk, 1993; Anyamba, et al, 2001). PCA allows any set of original satellite imageries to be transformed to a set of new images (referred to as components) where such component images contain all of the information in the original images entered into such time-series are uncorrelated with one another (Richards, 1984). The interpretation of the extracted component images thus, rely on a combination of spatial and temporal analysis.

Studies have been conducted to sensitize relevant authorities and stakeholders in taking necessary measures in dealing with the threat of the trypanosome vector rather than wait until an outbreak. Such awareness is paramount due to the prevalence of the disease and the high rate of livestock mortality reported whenever there is a breakout (Kalu, 1996; Ameh et al., 2000). In addition, this is relevant for countries such as Nigeria and in particular, Northern Nigeria where livestock production is the main source of people's livelihoods and the power house of livestock products for many other parts of the country. This present study demonstrates a cost effective approach of the use of remotely sensed data analysed using GIS in highlighting probable habitats of vectors responsible for trypanosomiasis diseases in northern Nigeria.

\section{MATERIALS AND METHOD}

\subsection{Description of Study Area}

The study area is Northern Nigeria (Figure 1), of the Federal Republic of Nigeria. Nigeria, covering an area of $923,768 \mathrm{~km}^{2}$ is located at Latitudes $04^{\circ} .15^{\prime}$ to $14^{\circ} .00^{\prime} \mathrm{N}$ and Longitude $02^{\circ}$ $.23^{\prime}$ to $14^{\circ} .91^{\prime} \mathrm{E}$ is bounded to the north by Niger Republic, to the west by Benin Republic, to the east by Chad and Cameroun, and to the south by the Atlantic Ocean. The climate of Nigeria which varies from the north to the south of the country is mainly: the dry season and the wet seasons. There is variation in rainfall from the northern to the southern part and it is attributed to the fluctuation of the ITCZ (Oguntoyinbo, 1982).

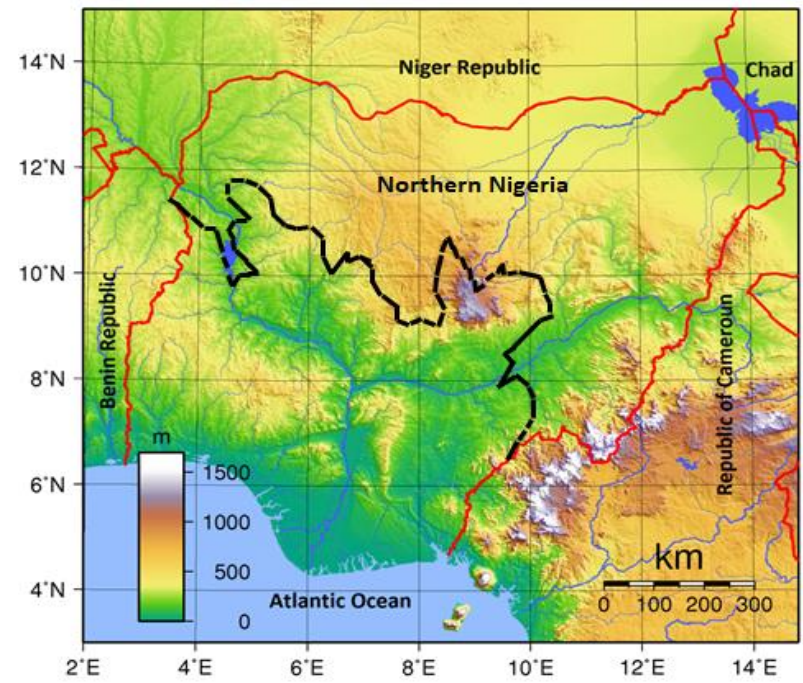

Figure 1. Map of Nigeria showing northern Nigeria and elevations of Nigeria

The ITCZ reaches its northernmost position near the 19th parallel in mid-August, when Sahel rainfall peaks, and after August, retreats rapidly southwards from June to September. Rainfall of less than $500 \mathrm{~mm} / \mathrm{a}$ occur in some parts of the north and up to $1200 \mathrm{~mm} / \mathrm{a}$ in other parts. In the south, rainfall range between $1200 \mathrm{~mm} / \mathrm{a}$ to over $2600 \mathrm{~mm} / \mathrm{a}$. In the north, the mean monthly temperatures during the hottest days can exceed $36^{\circ} \mathrm{C}$ reaching $45^{\circ} \mathrm{C}$ a times while the mean monthly temperatures at night in many cases is $22^{\circ} \mathrm{C}$. Temperatures in the south are much lower ranging mostly between $28^{\circ} \mathrm{C}$ and $37^{\circ} \mathrm{C}$ with minimum temperatures reaching $18^{\circ} \mathrm{C}$. From the north to the south, the climate of Nigeria is classified into the warm desert climate, warm semi-arid climate, the monsoon climate, and tropical savannah climate. Ecologically, Nigeria is divided into: The Sahel Savana, Sudan Savana, Guinea Savana Rainforest, and the Mangrove swamp from the north of the country to the south.

It is important to note that while the areas that are classified geopolitically as northern Nigeria are considered in this study, other areas falling in the central parts of the country known as the north central parts are also considered north here as grazing extends to these areas and there are rivers which could be probable habitats for arthropods in the areas.

\subsection{Data Sources and methodology}

The procedure for conducting this study is presented in the flow chart in Figure 2. 


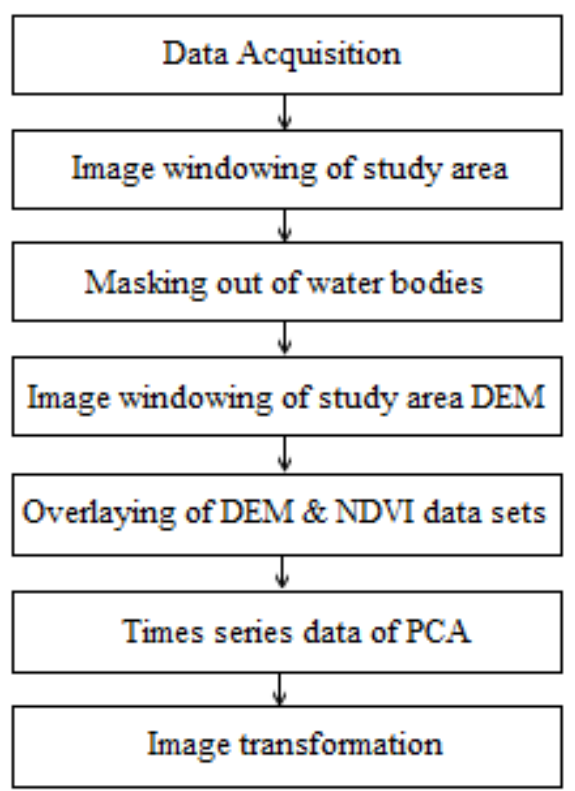

Figure 2. Study procedure

For this study, data for 5 years from 2005 to 2009 amounting to sixty (60) monthly time-series satellite imagery in the form of Normalized Difference Vegetation Index (NDVI) at 250 meter spatial resolution was acquired from National Aeronautics Space Administration (NASA)'s Moderate Resolution Imaging Spectrometer (MODIS ) Climate Modelling Grid (CMG) where the coordinates corresponding to the study area covering the northern part of Nigeria was windowed using the Idrisi Andes raster-based remote sensing and GIS software.

Water bodies were masked out to zero in order to ease the analysis. Digital Elevation Model (DEM) of the study area was also windowed and overlaid with the NDVI dataset to supplement the analysis. The time series data was subjected to Principal Component Analysis utilizing the standard principal components where of original satellite imageries were transformed to a set of new images (referred to as components). These resultant component images contain all of the information in the original images entered into such time-series but are however, uncorrelated with one another. DEM covering the study area was also windowed to conform with the original coordinates of the NDVI time-series data so as to supplement the analysis, by determining the approximate elevation of the probable areas that serve as habitats for these disease vectors.

\section{RESULTS}

Results from this study produced two outputs namely, sixty (60) component images and their respective sixty (60) standard scores, referred to as 'Component loadings'. Although there are up to this number of component images of loading score, the preliminary analysis is limited to only four components as more ground trothing and environmental data is required to conduct further assessment. The study conducted by Rogers et al (1997) using NDVI covering the whole country, revealed spatial patterns of NDVI relating to seasonal and annual variations across the whole country, in addition to a pattern of changes which likely relate to localized events such as possible habitats of the vectors responsible for Trypanosomiasis diseases.

Accordingly, the resulting component 2 to 4 images from the PCA analysis of this NDVI time-series dataset suggests that there are some environmental implications particularly resulting from breeding habitats for vector-borne diseases as a result of global climate change and climatic variability which correlates with studies conducted by Matzke, 1983; Anene, et al, 1991; Hay, 1997; Kalu, 1995, 1996; Patz, et al; 2000, Ameh, et al, 2000). For most of the pockets vegetated areas that are indicative of either negative or positive anomalies as the PCA results have shown, representing areas of ecological zones of special concern. A look at the loading graphs of these components and the digital elevation model overlaid on them to supplement the analysis indicates that the areas that are vulnerable are those above 1000 meters above mean sea level around mountain areas of Plateau and Adamawa States. On the other hand, other areas that serve as probable habitats are along the river banks between 300 to 600 meters above sea level.

In Figure 3, the component image explains about $81 \%$ of the total variance in the 60 NDVI time series dataset used in the PCA procedure. It illustrates a representative vegetation pattern across Northern Nigeria and partly from southern part of Niger Republic. Republic of Benin and Cameroon. This image looks similar to the NDVI. Areas that are less correlated with the loading scores are located from the northwest to the northeast ecological zones generally appearing in brown (when viewed in color) indicating less vegetation vigor. On the other hand, areas that are highly correlated with the loading scores are located in the southern part of the northern fringes and pockets of reserved areas (located partly in, Kogi, Benue and Taraba States and partly falling in republic of Cameroon) appearing in green colors indicating more vegetation vigor. The loadings score on the other hand show positive correlations between the component image and the entire NDVI time series dataset. The higher peaks are located in November, 2005, 2006 and 2008 while the lower peaks on the graph are located in August 2005, August 2006 and September, 2007.
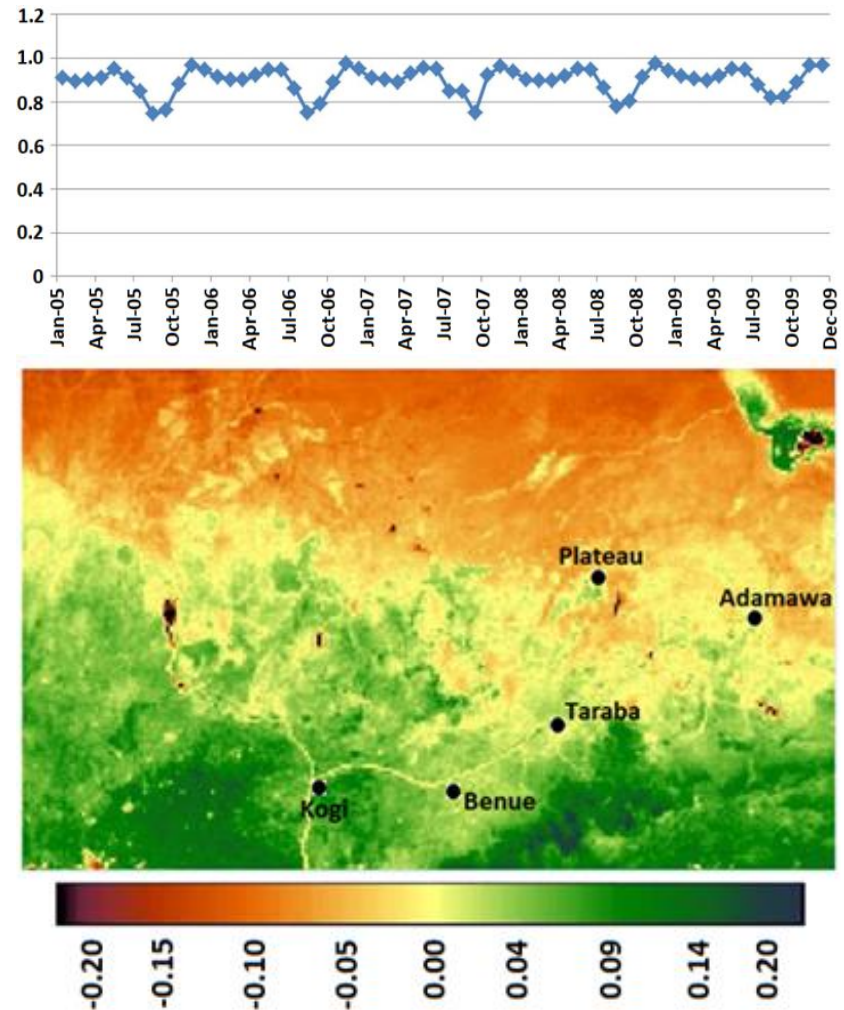

Figure 3. Component 1 image and its corresponding graph of loadings 
Component 2 image in Figure 4 is an illustration of the first change component that differs from Component 1 explaining about $8 \%$ of the total variance of the original time- series dataset used as input in the PCA procedure. Its corresponding loading graph shows a pattern of cyclic trend showing positive scores and peaks mostly in September of each year except in August 2006 while negative scores with lower peaks are mostly in February and March. The positive peaks correspond with the peaks of rainy seasons in most areas across the whole study area cantered on Northern Nigeria, while the negative peaks correspond with the dry seasons between January and March of each year.

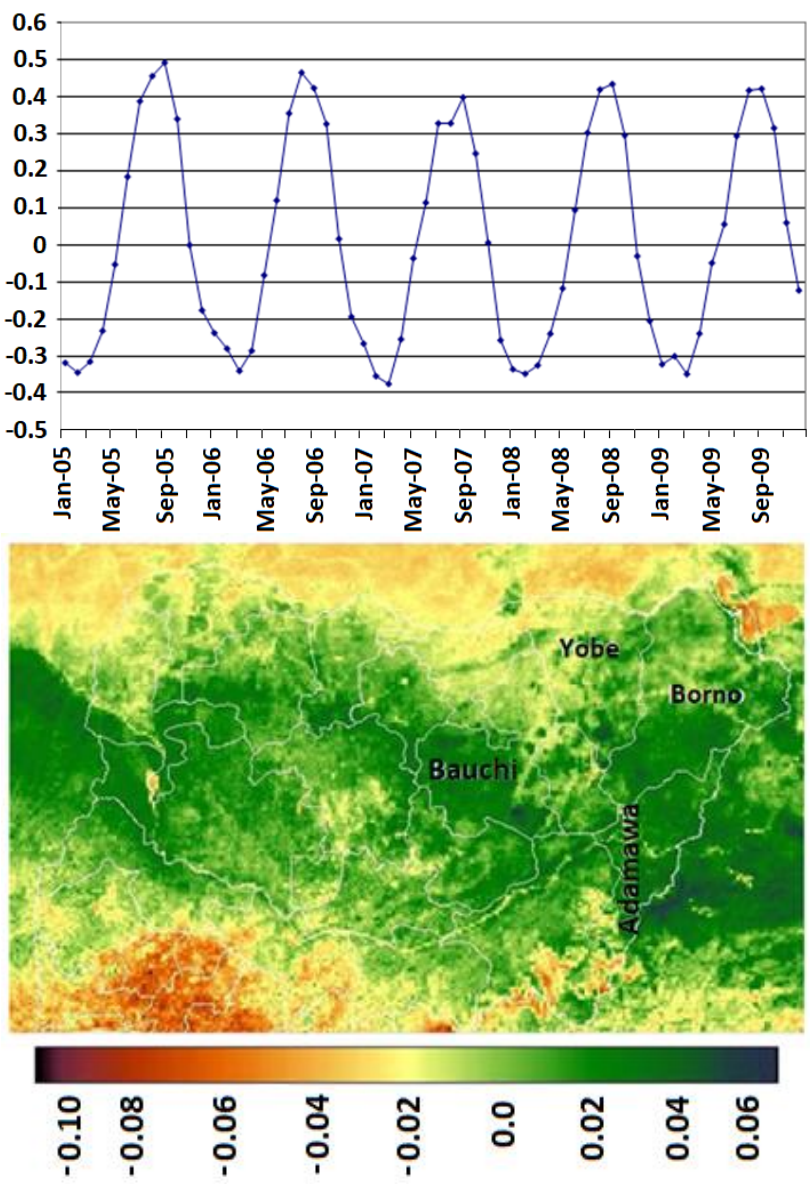

Figure 4. Component 2 image and its corresponding graph of loadings

This suggests that reservoirs, irrigation canals, and dams are closely associated with parasitic disease. Road and other constructions that disturb vegetation generally can alter ecological balance and can lead to a shift in vector populations such as snails, mosquitoes, their larva and their parasites. There are high positive correlation spotted in Bauchi, Yobe and Borno states as well as the border areas between Adamawa state and the neighbouring Cameroon. However, there are also signs of high negative anomaly patterns around Kainji and Lake Chad, along river Niger and Benue as well as areas around the forest zones of the southwestern part of the Country.

Figure 5 shows the Component 3 image which represents the second change component image exhibiting about $1.9 \%$ of the variation in the NDVI dataset utilized in the analysis. The corresponding graph of loading scores of this component image, though semi-circular, looks similar to Component 2 in terms of cyclic pattern of vegetation change as shown by the graph of its loading scores. However, the peak of the positive scores on the graph fall in January and September for most years while the negative (low) peaks fall mostly in the month of May. On this component image unlike Component 2 image, most of the positive anomaly patterns are located around forest islands characterized by dry woodland and savanna and along lowland and riverine areas such as the Hadejia-Jama' are and River Rima basins. High negative anomaly patterns however, are located around major dam areas across the northern part of the country. This fluctuated pattern, in the profile during this period is an Indicative of aggregate effect of temperature, precipitation, humidity, solar radiation, and wind which are reflected in the type of vegetation in plant communities contribute to determining the nature of vector populations.
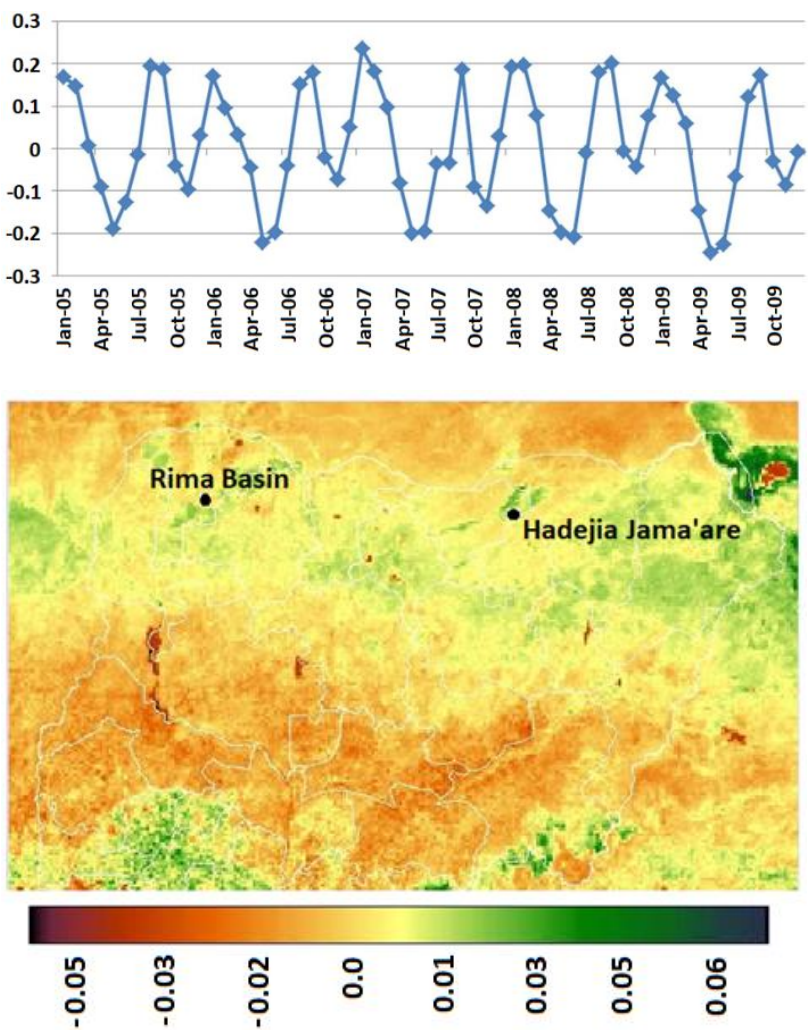

Figure 5. Component 3 image and its corresponding graph of loading

Figure 6 which is the Component 4 image of third change component image shows about $1.2 \%$ of the total variation in the NDVI time-series dataset. The graph of loading for this component image also shows some form of cyclic trend with all positive peak scores on the graph falling in October of all the years. The negative score lower peaks, on the other hand, are mostly in July and August. This component image shows a positive anomaly (mostly in green) across the entire northern part of the country with corresponding strong negatively anomalies along rivers Niger and Benue and extensively covering parts of Borno and Yobe States. This is unrealistic given the geographical and climatic locations of these different pixels. According to Patz et al, 2000 river blindness is most common along the main river valleys. For example, in Plateau state, the vectors breed during the wet season and peak biting density occurs at the height of the rainy season, with more infective parasites at the beginning and end of rains. 


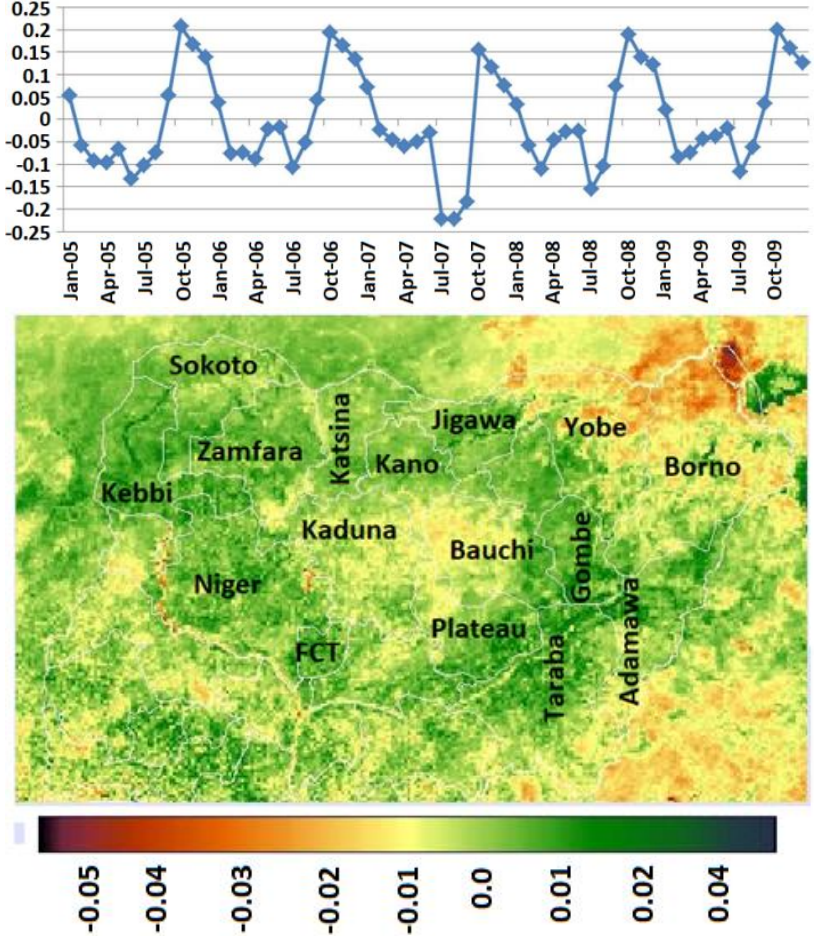

Figure 6. Component 4 image and its corresponding graph of loading

\section{DISCUSSION}

The use of PCA as a technique for detecting spatial changes of probable habitat of vectors responsible showed that this costeffective method can be utilized across northern Nigeria in a systematic way. Temporal profiles of anomalous NDVI pixels selected from areas that showed change patterns on component images gave further clues of possible long-term climatic events which the graph of loading scores highlighted.

As it is not economically feasible to raise cattle for example, on large areas of the land due to high prevalence of tsetse flies, cattle breeding/ranching if often confined to dry areas where tsetse flies cannot survive. However, overstocking of these animal is likely to cause land degradation and overgrazing. Furthermore, when there is deforestation in the form of farm extensions and constructions forested areas particularly in the savanna areas of the northern part of Nigeria is replaced by different types of tall crops thereby providing comfortable habitat for tsetse colonization. This cost-effective approach where remotely sensed data analysed within a GIS environment if adopted can assist in highlighting probable habitats of vectors responsible for trypanosomiasis diseases. These habitats when identified can easily be targeted with the aim of eradicating the vectors. A higher spatial resolution data such as the one provided by the Nigeria satellite system as well as other environmental information combined can effectively enhance further studies of highlighted areas of the probable habitat of these vectors of disease.

\section{ACKNOWLEDGEMENTS}

The authors would like to acknowledge National Aeronautics Space Administration (NASA) for providing open-access data of satellite images for the specific area. This study is supported by Research University Grant number GUP Q. J130000.2627.13J88 from Universiti Teknologi Malaysia. The authors would equally like to extend their appreciation to the
Petroleum Technology Development Fund (PTDF) of Nigeria for the substantial financial support of this study.

\section{REFERENCES}

Ameh, J. A., Egwu, G. O. and Tijjani, A. N. (2000). Mortality in Sahelian goat's in Nigeria. Preventive Veterinary Medicine. 44, $107-111$.

Anene, B. M., Chime, A. B., Jibike, G.I. and Anika, S. M. (1991). Prevalence of trypanosomiasis in Zebu cattle at Obiudu ranch - a tsetse-free zone in Nigeria.

Anyamba, A. and Eastman, J. R. (1996). Interannual variability of NDVI over Africa and its relation to El-Nino/Southern Oscillation. International Journal of Remote Sensing, 17, 2533-2548

Anyamba, A. and Eastman, J. R. (1996). Interannual variability of NDVI over Africa and its relation to El-Nino/Southern Oscillation. International Journal of Remote Sensing, 17, 2533-2548.

Anyamba, A., Tucker, C. J. and Eastman, J.R. (2001). NDVI anomaly patterns over Africa during the 1997/98 ENSO warm event. International Journal of Remote Sensing, 22, 1847 1859.

Anyamba, A., Linthicum, J., Mahoney, R., Tucker, C.J. and Kelley, P.W. (2002). Mapping potential risk of Rift Valley fever outbreaks in African Savanna using Vegetation Index Time Series Data. Photogrammetric Engineering and Remote Sensing, 68, 137 - 145.

Bourn, D., Wint, W., Blench, R. and Wolley, E. (1994). Nigerian livestock resources surveys. World Bank Animal Review, 78, 49 - 58.

Dransfield, R. D., Williams, B. G. and Brightwell, R. (1991). Control of tsetse flies and trypanosomiasis: myth of reality. Parasitol Today, 7, 287 - 291.

Eastman, J. R. and Fulk, M., (1993). Long sequence time series evaluation using standardised principal components. Photogrammetric Engineering and Remote Sensing, 59, 991-996.

Hay, S. I., Packer, M. J. and Rogers, D. J. (1997). The impact of remote sensing on the study and control of invertebrate intermediate hosts and vectors for disease. International Journal of Remote Sensing, 18, 2899 - 2930.

ILRAD (1993). International Laboratory for Research Animal Diseases. Estimating the costs of animal trypanosomiasis in Africa. 11 (2) 1- 4.

Joly, M. and Voldoire, A. (2009) Influence of ENSO on the West African Monsoon: Temporal Aspects and Atmospheric Processes. Americ. Met. Soc. Vol. 2, 3193 - 3210. DOI: 10.1175/2008JCLI2450.1

Kalu, A. U. (1995). Prevalence of trypanosomiasis among Trypanotolerant cattle at the lower Benue River area of Nigeria. Preventive Veterinary Medicine, 24, 97 - 103. 
Kalu, A. U. (1996). Current status of tsetse fly and animal trypanosomiasis on the Jos Plateau, Nigeria. Preventive Veterinary Medicine, 27, $107-113$.

Laird, M. (1977). Tsetse: The future for biological methods in integrated control. International Development Research Centre. Ottawa, Ontario. pp220.

Matzke, G. (1983). A Reassessment of the expected development consequences of tsetse control efforts in Africa. Social Science and Medicine, 17, 531-537.

Oguntoyinbo, J. S. (1982). Climate 2: Precipitation (1). In Barbour, K. M., Oguntoyinbo, J. S., Onyemelukwe, J. O. C. and Nwafor, J. C. (Editors) Nigeria in Maps, pp $16-17$. Hodder and Stoughton Ltd, London.

Patz, J. A., Graczyk, T. K., Geller, N. and Vittor, A. Y. (2000). Effects of Environmental change on emerging parasitic diseases. International Journal for Parasitology, 30, $1395-1405$.

Patz, J. A. (2001). Public Health Risk Assessment Linked to Climatic and Ecological Change. Human and Ecological Risk Assessment, 7, 1317 - 1327.

Richards, J. A. (1984). Thematic mapping from multitemporal images data using Principal Component transformation. Remote Sensing of Environment, 16, 35- 46.

Rogers, D. J., Hay, S. I. and Packer, M. J. (1996). Predicting the distribution of tsetse-flies in West Africa using temporal Fourier processed Meteorological Satellite Data. Annals of Tropical Medicine and Parasitology, 90, 225 - 241.

Rogers, D. J., Hay, S. I., Packer, M. J. and Wint, G. R. W. (1997). Mapping Land- cover over large areas using Multispectral data derived from the NOAA-AVHRR: A case Study of Nigeria. International Journal of Remote Sensing, 18, 3297-3303.

Shahid, S. (2010) Rainfall Variability and the Trends of Wet and Dry Periods in Bangladesh. Int. J. Climatol., 30, 2299-2313.

Shiru, M.S., Shahid, S., Alias, N., and Chung, E-S. (2018) Trend Analysis of Droughts during Crop Growing Seasons of Nigeria. Sustainability, 10, 871, 13pp. doi:10.3390/su10030871 Singh, A. and Harrison, A. (1985). Standardized Principal Components. International Journal of Remote Sensing, 6, 883896. (Richards, 1984).

Sutherst, R, W. (1998). Implications of global change and climatic variability for vector-borne diseases: generic approaches to impact assessments. International Journal for Parasitology, 28, 935 - 945.

Thomas, V. and López, R. (2015) Global increase in climate related disasters. Asian Development Bank (ADB) Economics working paper series. No. 466.

White, F. (1983). The Vegetation of Africa (Natural Resources Research Series, 20), Paris, UNESCO.

Yu, P., Habtemariam, T., Oryang, D., Obasa., M., Nganwa, D., and Robnett, V. (1995). Integration of temporal and spatial models for examining the epidemiology of African trypanosomiasis. Preventive Veterinary Medicine. 24, 83-95. 